\title{
Title
}

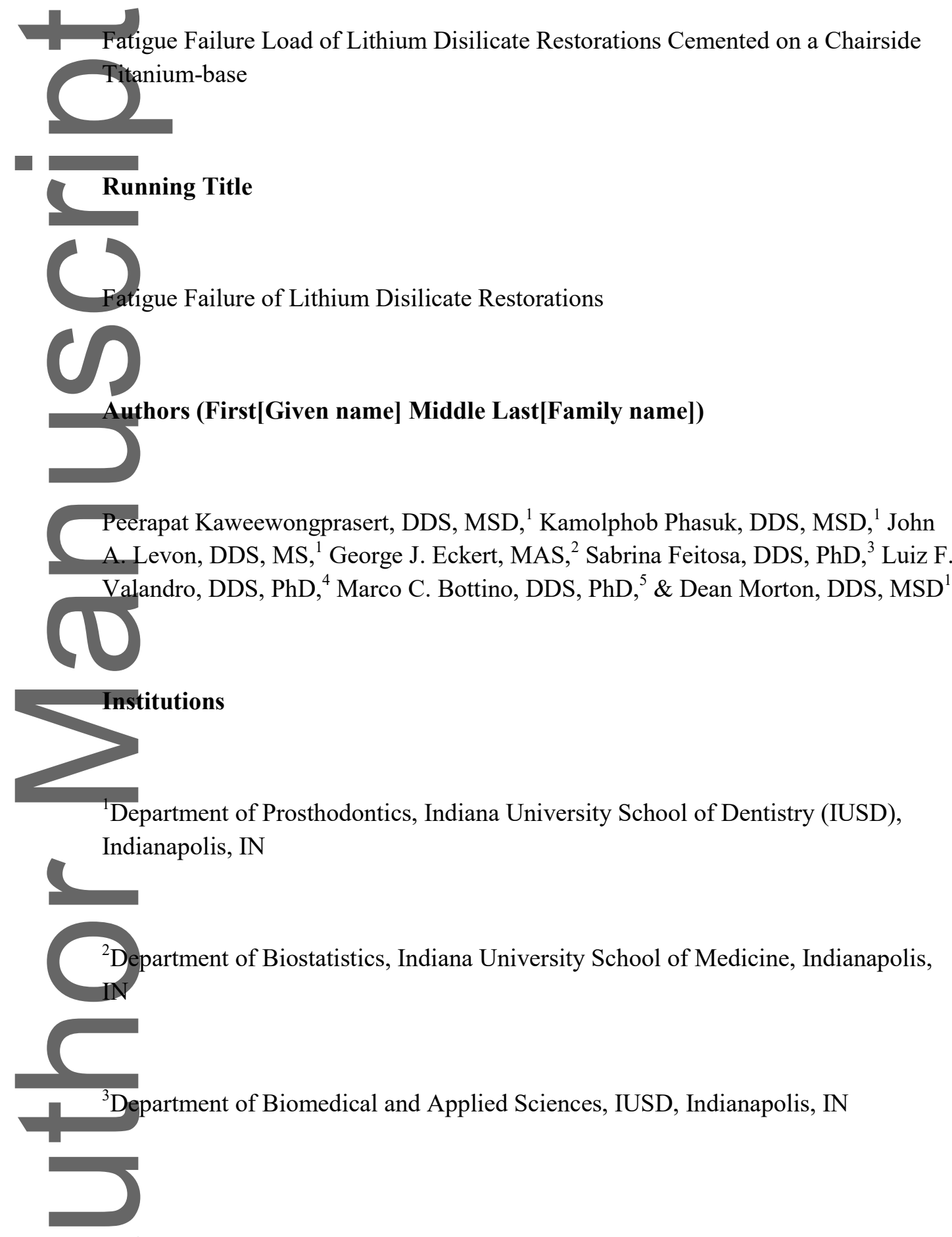

This is the al 1 manuscript accepted for publication and has undergone full peer review but has not been the wo tl copyediting, typesetting, pagination and proofreading process, which may lead to differences betw this version and the Version of Record. Please cite this article as doi: 10.1111/jopr.12911.

This article is protected by copyright. All rights reserved. 
${ }^{4}$ Department of Restorative Dentistry, Universidade Federal de Santa Maria -

UFSM, Faculty of Dentistry, Santa Maria, Brazil

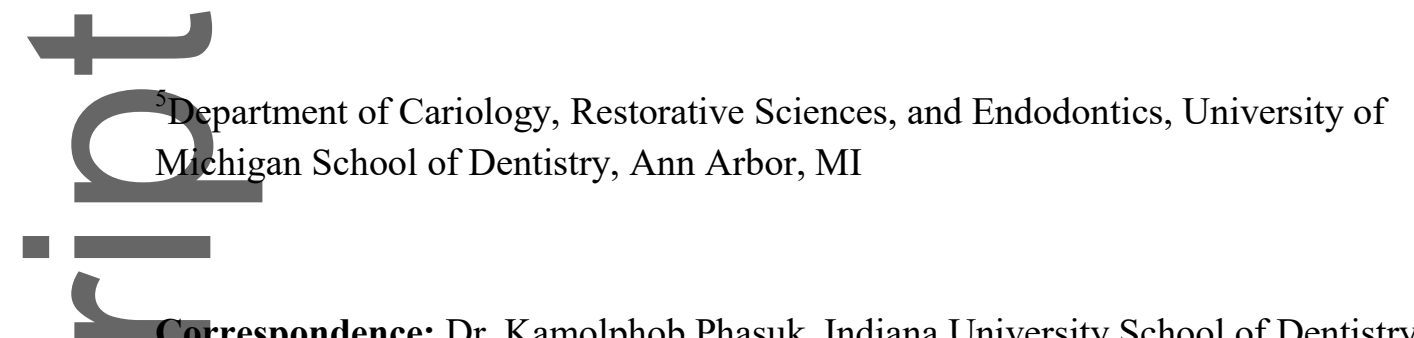

Dept. of Prosthodontics, 1121 W. Michigan St., Indianapolis, IN, 46202. E-

Mail:kphasuk@iu.edu.

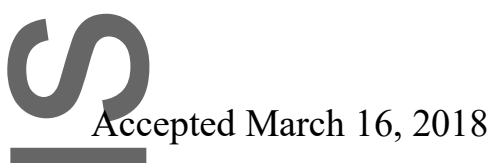

$\int$

Previously presented at: 2018 Annual Meeting of the Academy of Osseointegration, Los Angeles, CA, February 28 - March 3, 2018. This work received the 2nd place award in the e-poster category.

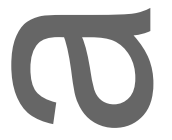

This manuscript is based on a thesis presented by Dr. Peerapat Kaweewongpraesert in fulfillment of Master of Science in Dentistry

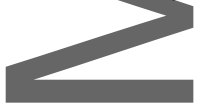

The authors declare that they have no conflicts of interest related to this study.

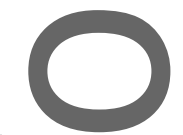

Abstract

Purpose: To evaluate the fatigue failure load of distinct lithium disilicate restoration designs cemented on a chairside titanium base for maxillary anterior implant-supported restorations.

Materials and Methods: A left-maxillary incisor restoration was virtually designed and sorted into 3 groups: ( $n=10$ /group; CTD: lithium disilicate crowns cemented on custommilled titanium abutments; VMLD: monolithic full-contour lithium disilicate crowns cemented on a chairside titanium-base; VCLD: lithium disilicate crowns bonded to lithium disilicate customized anatomic structures and then cemented onto a chairside titanium base).

This article is protected by copyright. All rights reserved. 
The chairside titanium base was air-abraded with aluminum oxide particles. Subsequently, the titanium-base was steam-cleaned and air-dried Then a thin coat of a silane agent was applied. The intaglio surface of the ceramic components was treated with 5\% hydrofluoric acid (HF) etching gel, followed by silanization, and bonded with a resin cement. The specimens were fatigued at $20 \mathrm{~Hz}$, starting with a $100 \mathrm{~N}$ load $(5000 \times$ load pulses $)$, followed by stepwise loading from $400 \mathrm{~N}$ up to $1400 \mathrm{~N}$ (200 N increments) at a maximum of 30,000 cycles each. The failure loads, number of cycles, and fracture analysis were recorded. The data were statistically analyzed using one-way ANOVA, followed by pairwise comparisons $(p<0.05)$. Kaplan-Meier survival plots and Weibull survival analyses were reported.

Results: For catastrophic fatigue failure load and the total number of cycles for failure, VMLD (1260 N, 175,231 cycles) was significantly higher than VCLD $(1080 \mathrm{~N}, 139,965$ cycles) and CDT $(1000 \mathrm{~N}, 133,185$ cycles). VMLD had a higher Weibull modulus demonstrating greater structural reliability.

Conclusion: VMLD had the best fatigue failure resistance when compared with the other two groups.

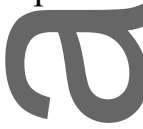

Keywords: Abutment fatigue; CAD/CAM; implant; lithium disilicate; stepwise; titanium.

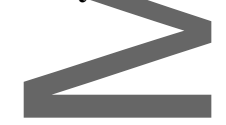

Implant-supported restorations have become widely accepted as one of the most predictable clinical modalities due to several factors, including but not limited to proven longevity and esthetics, making them a viable alternative to traditional fixed dental prostheses (FDPs) for single-tooth replacement. ${ }^{1-3}$ Although dental implant therapy is becoming more reliable, restoring implants in an esthetic zone is highly challenging, as the clinician has to carefully consider tooth form, occlusion, gingival contour, and restorative materials. ${ }^{4-8}$ Notably, the restorative design for each patient is dependent upon many determinants, including the interocclusal space, implant angulation, and dentogingival esthetics. ${ }^{6}$ Conventionally, a single implant restoration can be classified as screw-retained or cement-retained. When a cementretained restoration is indicated, either a prefabricated abutment or a castable custom 
abutment is used. ${ }^{6}$ A common challenge related to the cement-retained restoration is excess residual cement, especially at the interdental papilla in anterior teeth, which may lead to periimplantitis and eventually result in marginal bone loss. ${ }^{9}$

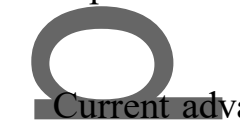

aided design and computer-aided manufacturing (CAD/CAM) technology to fabricate customized abutments. ${ }^{10,11}$ Several materials, including titanium and ceramics (e.g., lithium disilicate and zirconia), have been used. ${ }^{11}$ To date, titanium custom abutments represent the gold standard for single implant-supported restorations, due to their excellent material stability and biologic integration. ${ }^{12}$ The only drawback relates to the grayish color associated with titanium, which may interfere with the esthetic result, especially in the anterior maxillary region, as patients with thin gingival phenotype may show a metal color through the facial tissue. ${ }^{5,6,12}$ As an alternative, and to satisfy esthetic needs, not only the implant restoration has to be matched to the adjacent teeth, but also the shade and contour of the peri-implant mucosa also needs to be considered. ${ }^{6}$

Recently, a new technique using lithium disilicate ceramic connected to a titanium-base was introduced. ${ }^{13-15}$ Several in vitro studies ${ }^{16-18}$ have reported exceptional mechanical performance, including fracture strength and stiffness of the titanium-base when combined with a ceramic restoration. The lithium disilicate restoration can either be fabricated to a fullcontour anatomy, connected to the titanium base, or obtained as a customized anatomical structure and bonded to the titanium base, which is then clinically cemented to a lithium disilieate erown. ${ }^{17}$ These combined abutment solutions allow the clinician to fabricate either custom-milled screw-retained or cement-retained restorations with high esthetics and lower cost when compared to conventional abutments. ${ }^{14}$

The process of abutment customization and implant restoration generally takes between 10 and 14 days after implant impression. ${ }^{14}$ By using chairside CAD/CAM technology, a 
single implant restoration can be delivered to the patient within a day of making the implant impression. ${ }^{14}$ Several all-ceramic restorative designs can achieve an esthetic outcome for restoring maxillary anterior implant-supported restorations. Previous studies ${ }^{19-23}$ have mainly focused on the performance of laboratory-fabricated zirconia abutments, but only a few investigations ${ }^{13,15}$ have evaluated the mechanical properties, including the fatigue behavior of lithum disilicate connected with the chairside titanium-base using different designs. Thus, the present study sought to determine fatigue failure load and the number of cycles for failure of different designs of lithium disilicate restorations fabricated by chairside CAD/CAM technique connected to a titanium base using an accelerated fatigue test. The null hypothesis of this study was that there would be no significant differences in outcomes among the lithium disilicate restoration designs connected with the chairside titaniumbase.

\section{MATERHALS AND METHODS}

\section{Studydesign}

All materials and instruments used in this study are listed in Table 1. The study was designed to have three groups $(\mathrm{n}=10)$, namely: CTD: lithium disilicate crowns cemented on custommilled titanium abutments; VMLD: monolithic full-contour lithium disilicate crowns cemented on a chairside titanium base; and VCLD: lithium disilicate crowns bonded to lithium disilicate customized anatomic structures and then cemented onto a chairside titanium

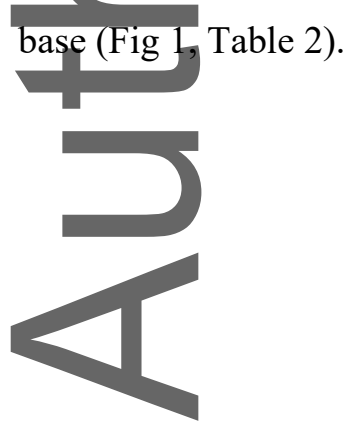

This article is protected by copyright. All rights reserved. 


\section{Specimen fabrication}

An-epoxy resin-glass fiber composite ${ }^{24}$ (NEMA Grade G10; Elastic modulus: $18.62 \mathrm{GPa}$, Piedmont Plastics, Charlotte, NC) was cut into $30 \times 30 \times 30 \mathrm{~mm}$ blocks. Thirty Straumann RC bone-level $4.1 \times 10 \mathrm{~mm}$ implants (Institute Straumann AG, Basel, Switzerland) were placed into a specimen holder and embedded in NEMA G10 blocks. ${ }^{25}$ A surgical template was designed using AutoCAD (Autodesk, Inc., San Rafael, CA) and 3D printed with standard clear resin (FormLab2 Printer; Formlabs, Inc., Somerville, MA). Lastly, a metal sleeve for Straunann Guided Surgery (Institute Straumann AG) was fitted to the prepared hole on the surgical template. Next, a pilot drill $(2.2 \times 36 \mathrm{~mm})$, twist drills $(2.8 \times 36 \mathrm{~mm}$ and $3.5 \times$ $36 \mathrm{~mm})$, and a set of guided profile drills, namely bone level $(4.1 \times 37 \mathrm{~mm})$, guided taps for bone level $(4.1 \times 42 \mathrm{~mm})$, one-dot $(2.2,2.8$, and $3.5 \mathrm{~mm})$ drill handle, and C-handle $\mathrm{H}-4$ from the surgical kit (Institute Straumann AG) were used to prepare the channel, along with the drill-press machine and surgical template. Channels (7 mm deep) were drilled on the specimen holder using the same surgical template throughout the experiment. A marginal bone loss of $3.0 \pm 0.5 \mathrm{~mm}$ from the nominal bone level was applied. All dental implants were embedded into NEMA G10 blocks through a surgical template using implant driver and manual torque wrench. The timing of the implant was controlled by lining up the flat surface on the implant mounted to the indentation line on the surgical template. The insertion torque value was tested with a manual torque wrench and determined to be greater than $35 \mathrm{Ncm}$. All of the tested specimens were randomly labeled and numbered.

Twenty left maxillary anterior incisor VCLD and VMLD restorations were virtually designed (CEREC 4.4 Software; Dentsply Sirona, York, PA) and fabricated (CEREC inLab MC XL; Dentsply Sirona) according to the specific design. All lithium disilicate ceramic specimens (pre-crystallized state) were pre-polished with a diamond rubber polisher, followed by fine-polishing with a high-gloss rubber polisher and polishing paste. Then, the specimens 
were cleaned in an ultrasonic bath with deionized water for 3 minutes, rinsed, and oil-free airdried. The specimens were taken to a dedicated furnace to complete the crystallization firing cycle (Programat CS furnace; Ivoclar Vivadent, Amherst, NY).

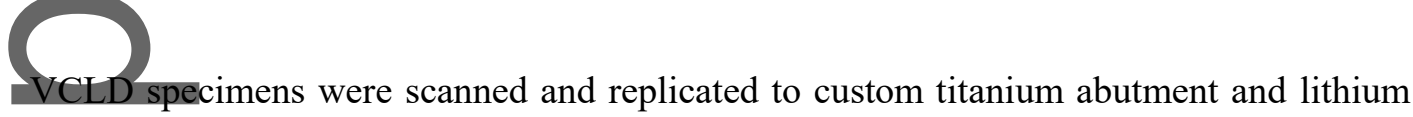
disilicate crowns (CTD group) using a desktop scanner (7Series Straumann powered by Dental Wings, Straumann CARES ${ }^{\circledR}$ Visual 10.3 software). Ten custom titanium abutments and lithium disilicate crowns (CTD) were fabricated from the Straumann Milling Center (Arlington, TX).

\section{Preparation of titanium base}

For VMLD and VCLD, the titanium base (Straumann Variobase for CEREC; Institute Straumann AG) was connected to an implant analog by hand-tightening the basal screw. A silicone fast set was used to protect the emergence profile and the screw channel of the implant analog. The titanium base was air-abraded with 50- $\mu \mathrm{m}$ aluminum oxide particles at 2 bars, at distance of $10 \mathrm{~mm}$ for 10 seconds, or until a matte surface was achieved. Subsequently, the abutment was steam-cleaned and air-dried, and a thin coat of silane (Monobond Plus; Ivoclar Vivadent) was applied for 60 seconds. The screw channel was protected with Teflon tape.

\section{Surface treatment and bonding}

For VCLD, the customized anatomic structure was cleaned in an ultrasonic bath with deienized water for 3 minutes. Then, the intaglio surface of the screw channel was etched with 5\% HF (IPS Ceramic etching gel; Ivoclar Vivadent) for 20 seconds, rinsed with deionized water for 60 seconds, ultrasonically cleaned in a bath of deionized water for 5 minutes, air-dried, and silanized. After bonding between the titanium base and the customized anatomic structure was completed, the bonding interface of the customized anatomic 
structures was prepared using a similar protocol, as was the intaglio surface. The CTD crowns, VMLD crowns, and VCLD crowns were cleaned in an ultrasonic bath with deionized water for 3 minutes. The intaglio surface was etched with $5 \%$ HF for 20 seconds, rinsed for 60 seconds, cleaned in an ultrasonic bath with deionized water for 5 minutes, air-dried, and silanized.

For $\mathrm{CTD}$, the custom titanium abutments and RC basal screws were autoclaved (moist
heat at $134^{\circ} \mathrm{C}$ for 18 minutes). Next, the custom titanium abutments and RC basal screws were gonnected onto dental implants embedded in the specimen's holder and torqued up to $35 \mathrm{Nem}$ using a manual torque wrench. Each abutment screw was re-torqued to a final torque value of $35 \mathrm{Ncm}$ after 10 minutes from the initial torque. The abutment access channel was protected with Teflon tape $2 \mathrm{~mm}$ from the top of the palatal surface. The screw channel was filled with implant channel filling material (Telio CS Inlay Universal; Ivoclar Vivadent). The filling material was cured with a light-emitting diode (LED) curing light (Bluephase 20i; Ivoclar Vivadent) for 10 seconds (light intensity $>650 \mathrm{~mW} / \mathrm{cm}^{2}$ ). The curing light was calibrated (Cure Rite; Dentsply Caulk, Milford, DE) before use. All surface-treated crowns were cemented to the custom titanium abutments with resin cement (Multilink Automix; Ivoclar Vivadent). The excess luting agent was removed with a microbrush. Glycerin gel was then applied at the crown margin. A load of $300 \mathrm{~g}$ was applied on the incisal edge until autopolymerization completion to ensure an even film thickness. After autopolymerization completion, the glycerin gel was rinsed off with deionized water.

For VMLD, a thin layer of resin cement was directly applied from the mixing syringe to the bonding surface of the titanium base and the intaglio surface of the monolithic crown. Both components were connected, and the position markings were aligned. Excess resin cement was removed using a microbrush. Then, glycerin gel was applied at the crown margin. The specimens were held immobile with diamond-coated tweezers until autopolymerization 
completion, and then the glycerin gel was rinsed off with deionized water. The Teflon tape was removed, and excess luting agent cleaned off with a microbrush. The combination of the titanium base and monolithic crown was autoclaved. Then, the combination of the titanium base, monolithic crown, and basal screw were connected onto dental implants embedded in the specimen holder in a similar fashion to the CTD group, except that the rest of the channel was filled with resin composite. The resin composite was light-cured for 10 seconds (high power mode, light intensity $>1000 \mathrm{~mW} / \mathrm{cm}^{2}$ ).

For VCLD, a resin cement was applied between the titanium base and the customized anatomic structures. The excess resin cement was removed using a microbrush. Then, glycerin gel was applied at the crown margins. After autopolymerization completion, the glycerin gel was rinsed off with deionized water. The combination of the titanium base and customized anatomic structures was autoclaved, as described previously. Afterwards, the combination of the titanium base, customized anatomic structures, and basal screw were connected onto the implants embedded in a specimen holder in a similar fashion to the CTD group. All surface-treated crowns were bonded to the customized anatomic structures with resin cement. The excess luting agent was removed with a microbrush. Then, glycerin gel was applied at the crown margins. The specimens were subjected to a $300 \mathrm{~g}$ load on the incisal edge. After autopolymerization completion, the glycerin gel was rinsed off with deionized water. All specimens were soaked and stored in an incubator at $37^{\circ} \mathrm{C}$ for 24 hours before testing.

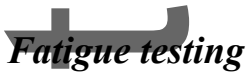

Dynamic fatigue testing of the dental implants was performed based on ISO14801:2007. ${ }^{26}$ All speeimens were positioned at $38^{\circ} \pm 2^{\circ}$ to the long axis of the prosthesis. The universal testing machine (Instron ElectroPuls E3000; Instron Corp., Norwood, MA) was calibrated before the start of the measurements and run by a well-trained operator. ${ }^{27}$ The fatigue loading test was 
run in dry conditions at room temperature $\left(20^{\circ} \mathrm{C} \pm 5^{\circ} \mathrm{C}\right)$. The load was applied using a stainless-steel round tip (10 mm diameter), which was centrally positioned at the palatal surface $1 \mathrm{~mm}$ from the incisal edge. A custom-made device was prepared using clear custom tray material (Triad TruTray VLC; Dentsply Sirona) and a clear vacuum sheet to ensure a reproducible position of the stainless steel round tip. The position was double-checked with the repositioning device and a double-sided articulating film (AccuFilm II; Parkell, Inc., Edgewood, NY) before each test. ${ }^{27}$ Once the position was confirmed, double-sided tape and transparent film were attached to the palatal surface of the specimens to facilitate even force distribution. Cyclic loading was programmed using the dedicated software (Bluehill 2.0; Instron Corp.) and applied at $20 \mathrm{~Hz}$, starting with a load of $100 \mathrm{~N}$ for 5000 cycles for preconditioning the specimens, followed by the compressive load staged at 200, 400,600, $800,1000,1200$, and $1400 \mathrm{~N}$ at a maximum of 30,000 for each cycle (200 N step size). ${ }^{27}$ All specimens were tested until either a catastrophic failure or the maximum of 215,000 cycles was reached. ${ }^{28}$ If the specimen survived $1400 \mathrm{~N}$ without failure, the maximum load $(1400 \mathrm{~N})$ and number of cycles $(215,000$ cycles, i.e., sum of cycles from the preconditioning step and all of the 7 load stages) were recorded. Initial failure was described as an implant deformation, abutment screw deformation, abutment deformation, crack, or craze line on the ceramic structure, prior to catastrophic failures. Catastrophic failure was defined as the fragmentation of any components. ${ }^{27}$

\section{Fracture analysis}

All speeimens were examined ( $5 \times$ magnification) initially and reevaluated at the end of each load under optical light microscopy (Leica MZ 125; Leica Microsystems GmbH, Wetzlar, Germany) Jusing a digital camera (Canon EOS Rebel T3; Canon, Inc., Melville, NY). integrated digital camera (Leica DFC290 HD; Leica Microsystems GmbH) and software 
were used to record and analyze both the initial and catastrophic failures. Different magnifications were used to evaluate the different characteristics of each failure feature.

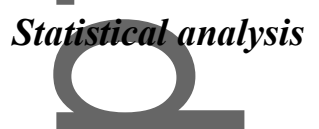

Group comparisons were made using one-way ANOVA, followed by pairwise comparisons if the overall group effect was statistically significant. The study was designed to have $80 \%$ power to detect a difference of $152 \mathrm{~N}$ for the maximum force between any two groups. In addition to the ANOVA, Kaplan-Meier survival plots and Weibull survival analyses were performed. A 5\% significance level was used for all tests.

\section{RESULTS}

For the initial fatigue failure load, VCLD was significantly lower than CDT $(p<0.05)$ and $\operatorname{VMLD}(p<0.05)$, while CDT and VMLD were not significantly different from each other. For catastrophic fatigue failure load, VMLD was significantly higher than CDT $(p<0.05)$ andVCLD $(p<0.05)$, which were not significantly different from each other. Moreover, the total number of cycles for the failure of VMLD was significantly higher than CDT $(p<0.05)$ and VCLD $(p<0.05)$, but CDT and VCLD were not significantly different from each other

\section{(Table 3).}

Surviyal probability of the Kaplan-Meier and Weibull models of initial failure, catastrophic failure, and number of total cycles, are illustrated in Figure 2. VMLD's Weibull modulus was higher than the other two groups, showing a higher structural reliability (lower data sc ata scattering) (Table 4). The mode of failure at the catastrophic failure load related to fracture locations is presented in Figures 3 and 4 and Table 5.

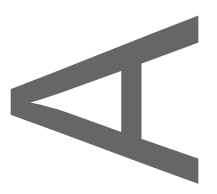




\section{DISCUSSION}

The null hypothesis of the current study was rejected, since the fatigue experiment showed that monolithic full-contour lithium disilicate crowns cemented on the chairside titanium base abutment (VMLD) survived a higher number of cycles for failure and had a higher fatigue failure resistance compared to the lithium disilicate crowns cemented on custom titanium abutment (CTD) and the lithium disilicate crowns bonded to lithium disilicate customized anatomic structures and then cemented on the chairside titanium base abutment (VCLD). The data showed that all the initial failures of the VMLD group were associated with the location of the screw channel. This finding suggested that the location of the screw channel might influence the mode of failure of the VMLD design based on the worst-case scenario of implant marginal bone loss. In contrast, findings from previous studies, ${ }^{15,29}$ which embedded the implant at the normal bone level, reported a permanent plastic deformation at the screw and internal connection of the titanium base without ceramic displacement or fracture. ${ }^{15}$

After observing the initial failure behavior, it was noted that the weakest component for the VCLD group is the lithium disilicate customized anatomical structure. The authors believe that increasing the lithium disilicate customized anatomical structure thickness might increase the fatigue failure load of the VCLD design; however, the thickness of the emergence profile is limited to the diameter of the titanium-base and implant.

The Kaplan-Meier and Weibull diagrams showed that the VCLD's initial failure load was the lowest in all three groups. The VCLD specimens also tended to have a longer time interval between initial failure and catastrophic failure, compared to the VMLD and CTD groups. Failure behavior from the VCLD group could be explained by the presence of resin cement between the ceramic structures. Previous studies ${ }^{30,31}$ had reported that bilayer ceramic 
cementation can limit or arrest subcritical crack growth in regions near the cement layer, agreeing with our findings.

(r)

A 70\% failure of the CTD group was due to fracture of the lithium disilicate crown with some custom titanium abutment deformation, which can be explained by the ceramic's brittle nature. ${ }^{32}$ However, the initial failure load of the CTD group was still significantly higher than the VCLP group. This could lead to the assumption that a lithium disilicate crown cemented on a custon titanium abutment might be able to better sustain fatigue loading. Meanwhile, the authors also found a 30\% failure mode represented as fracture at the tensile side of the abutment screws and implants across all three groups. This finding is in agreement with a previous study, ${ }^{25}$ which reported failures in similar locations when testing tissue-level implants in the worst-case scenario.

From the masticatory loading parameters standpoint, earlier studies by Gibbs et $\mathrm{al}^{33,34}$ reported an average mastication force in natural dentition at $720 \mathrm{~N}$. Particularly for the anterior region, there was a range of 150 to $235 \mathrm{~N}$, with an average of $206 \mathrm{~N} .{ }^{29,35}$ Considering the masticatory parameters and the present study findings, this can demonstrate that three restorative modalities could bear a greater load (Table 3) than normal chewing forces, ${ }^{34}$ agreeing with previous studies. ${ }^{15,29}$

In terms of fatigue testing, the International Organization for Standardization (IS014801:2007 Dynamic Fatigue Test for Endosseous Dental Implants) recommended testing a single endosteal and transmucosal dental implant under a worst-case scenario, located $3.0 \pm 0.5 \mathrm{~mm}$ from nominal bone level. ${ }^{26}$ The aforementioned guidelines also recommended either wet $\left(37^{\circ} \mathrm{C} \pm 2^{\circ} \mathrm{C}\right)$ or dry $\left(20^{\circ} \mathrm{C} \pm 5^{\circ} \mathrm{C}\right)$ test environments. In addition, the loading frequency shall be no more than $15 \mathrm{~Hz} \cdot{ }^{26}$ In contrast, a study by Fraga et al pointed out the relative time-consuming factor in fatigue loading all-ceramic restorations. ${ }^{27}$ The authors specified that fatigue strength was not different among frequencies 2,10 , and $20 \mathrm{~Hz}$

This article is protected by copyright. All rights reserved. 
in zirconia discs and suggested using up to $20 \mathrm{~Hz}$ to accelerate fatigue strength tests. ${ }^{27}$ Furthermore, the specimen holder was also specified by ISO standard to have a modulus of elasticity higher than $3 \mathrm{GPa}$, which will not deform the test specimens. Nevertheless, an in vitro study reported that this mounting material has an appropriate elastic modulus for a bone analog material ( $20 \mathrm{GPa})$, is easily machined, and is sufficiently tough for cyclic testing. ${ }^{25}$ One of the methods used to run an accelerated fatigue test is a stepwise protocol, which stimulates the failure of the restoration under fatigue circumstances at different load step sizes. ${ }^{27}$ First, it warms up a load of specimens for the specified number of cycles. Next, it steps-up levenly until reaching the upper limit of the testing. ${ }^{27,36}$ Several studies ${ }^{28,36,37}$ also employed the stepwise protocol to test restorations to accelerate fatigue failure.

The limitation of this study is the Bluehill fatigue loading software, which is not capable of automatically recording the early failure loads. The initial failure was visually observed at the end of each cycle under light microscopy. In addition, the axial loading of the specimens had to be meticulously monitored throughout the experiment, as well as running a no-sliding set-up. Taken together, future studies need to investigate the behavior of reduced diameter implants, abutment/crowns with different thicknesses, and restorative designs.

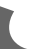

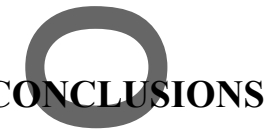

In accordance with the results of this study, the following conclusions may be drawn:

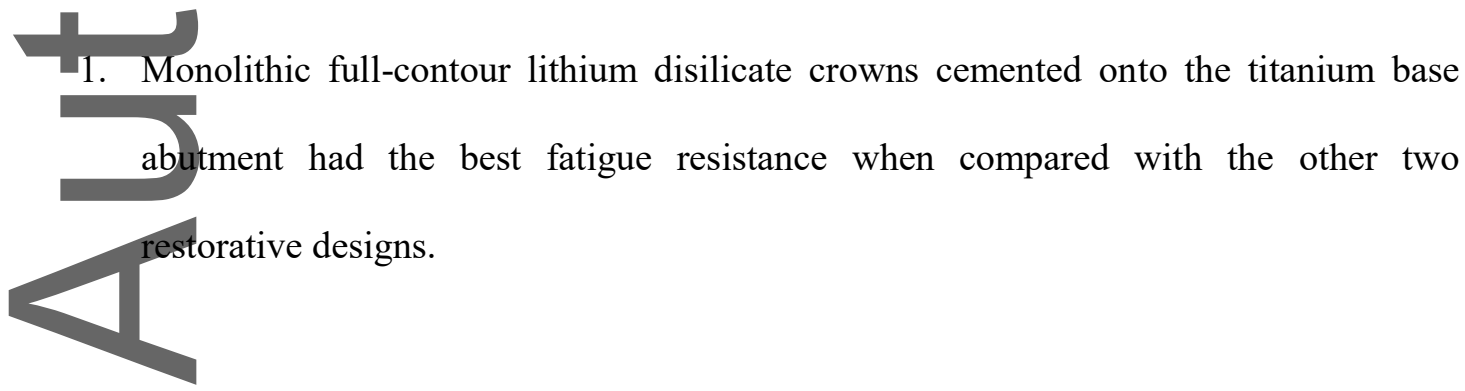

This article is protected by copyright. All rights reserved. 
2. Nonetheless, from a masticatory-loading standpoint, all three restorative approaches behaved well, since they had a high fatigue failure load in relation to masticatory

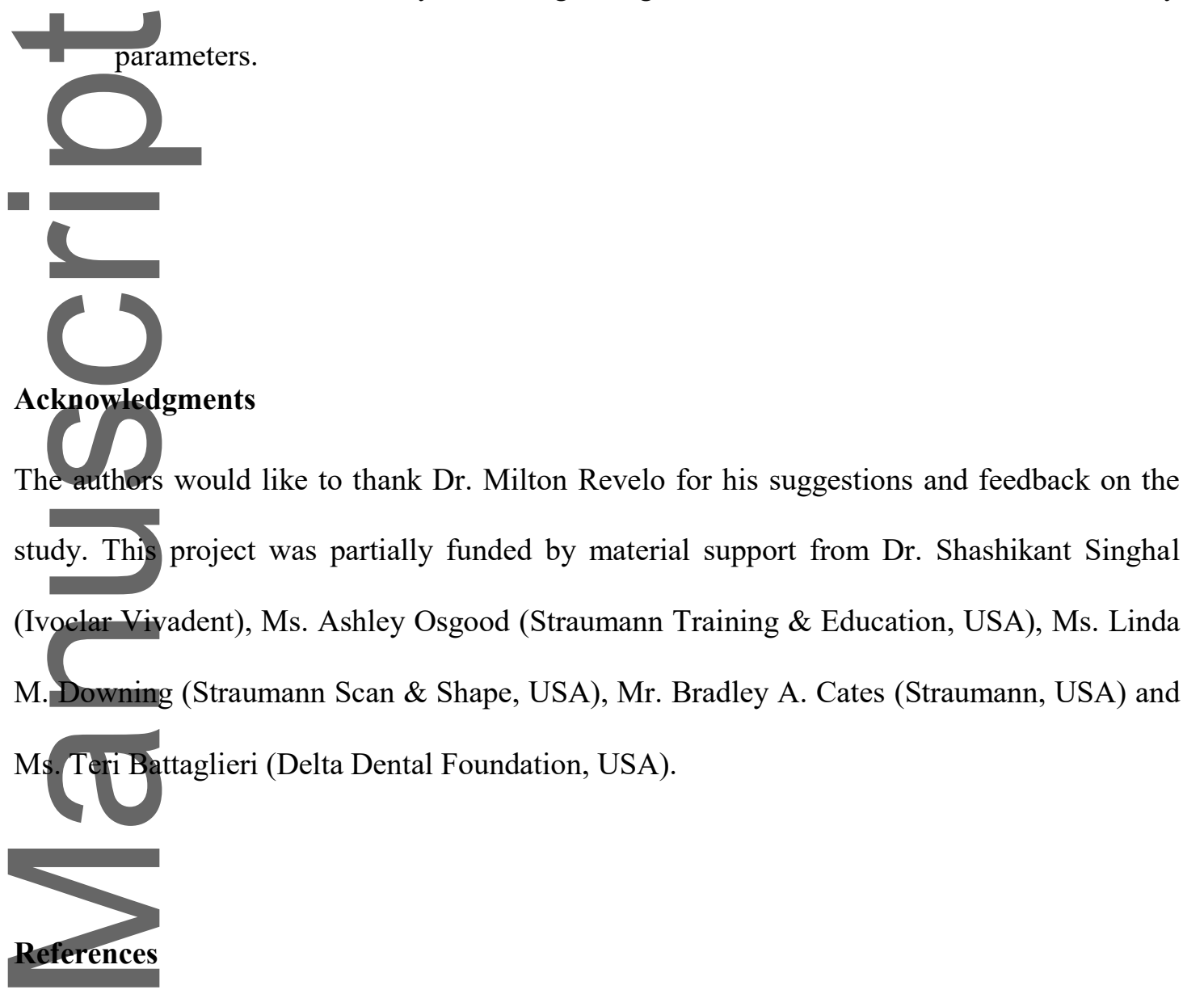

1. Adell R, Lekholm U, Rockler B, et al: A 15-year study of osseointegrated implants in the treatment of the edentulous jaw. Int J Oral Surg 1981;10:387-416

2. den Hartog L, Slater JJ, Vissink A, et al: Treatment outcome of immediate, early and conventional single-tooth implants in the aesthetic zone: a systematic review to survival, bone level, soft-tissue, aesthetics and patient satisfaction. J Clin Periodontol 2008;35:10731086

3. Pjetursson BE, Tan K, Lang NP, et al: A systematic review of the survival and complication rates of fixed partial dentures (FPDs) after an observation period of at least 5 years. Clin Oral Implants Res 2004;15:654-666

Jung RE, Pjetursson BE, Glauser R, et al: A systematic review of the 5-year survival and complication rates of implant-supported single crowns. Clin Oral Implants Res 2008;19:119-130

This article is protected by copyright. All rights reserved. 
5. Jung RE, Sailer I, Hämmerle $\mathrm{CH}$, et al: In vitro color changes of soft tissues caused by restorative materials. Int J Periodontics Restorative Dent 2007;27:251-257

6. Sailer I, Zembic A, Jung RE, et al: Single-tooth implant reconstructions: esthetic factors influencing the decision between titanium and zirconia abutments in anterior regions. Eur $\mathrm{J}$ Esthet Dent 2007;2:296-310

7. Belser UC, Grütter L, Vailati F, et al: Outcome evaluation of early placed maxillary anterior single-tooth implants using objective esthetic criteria: a cross-sectional, retrospective study in 45 patients with a 2- to 4-year follow-up using pink and white esthetic scores. J Periodontol 2009;80:140-151

8. Fürhauser R, Florescu D, Benesch T, et al: Evaluation of soft tissue around single-tooth implant crowns: the pink esthetic score. Clin Oral Implants Res 2005;16:639-644

9. Wadhwani C, Rapoport D, La Rosa S, et al: Radiographic detection and characteristic patterns of residual excess cement associated with cement-retained implant restorations: A clinical report. J Prosthet Dent 2012;107:151-157

10. Kapos T, Evans C: CAD/CAM technology for implant abutments, crowns, and superstructures. Int J Oral Maxillofac Implants 2014;29 Suppl:117-136

11. Ferrari M, Vichi A, Zarone F: Zirconia abutments and restorations: from laboratory to elinical investigations. Dent Mater 2015;31:e63-76

12. Marchack CB: A custom titanium abutment for the anterior single-tooth implant. J Prosthet Dent 1996;76:288-291

13. Joda T, Bürki A, Bethge S, et al: Stiffness, strength, and failure modes of implantsupported monolithic lithium disilicate crowns: influence of titanium and zirconia abutments. Int J Oral Maxillofac Implants 2015;30:1272-1279

14, Kurbad A, Kurbad S: CAD/CAM-based implant abutments. Int J Comput Dent 2013,16:125-141

15. Elsayed A, Wille S, Al-Akhali M, et al: Effect of fatigue loading on the fracture strength and failure mode of lithium disilicate and zirconia implant abutments. Clin Oral Implants Res 2018;29:20-27 
16. Abbo B, Razzoog ME, Vivas J, et al: Resistance to dislodgement of zirconia copings cemented onto titanium abutments of different heights. J Prosthet Dent 2008;99:25-29

17. Lin WS, Harris BT, Zandinejad A, et al: Use of prefabricated titanium abutments and customized anatomic lithium disilicate structures for cement-retained implant restorations in the esthetic zone. J Prosthet Dent 2014;111:181-185

18. Mühlemann S, Truninger TC, Stawarczyk B, et al: Bending moments of zirconia and titanium implant abutments supporting all-ceramic crowns after aging. Clin Oral Implants Res 2014;25:74-81

19. Stimmelmayr M, Sagerer S, Erdelt K, et al: In vitro fatigue and fracture strength testing of one-piece zirconia implant abutments and zirconia implant abutments connected to titanium cores. Int J Oral Maxillofac Implants 2013;28:488-493

20. Foong JK, Judge RB, Palamara JE, et al: Fracture resistance of titanium and zirconia abutments: an in vitro study. J Prosthet Dent 2013;109:304-312

21. Stimmelmayr M, Edelhoff D, Güth JF, et al: Wear at the titanium-titanium and the titanium-zirconia implant-abutment interface: a comparative in vitro study. Dent Mater 2012;28:1215-1220

22. Yilmaz B, Salaita LG, Seidt JD, et al: Load to failure of different zirconia abutments for an internal hexagon implant. J Prosthet Dent 2015;114:373-377

23.Att W, Yajima ND, Wolkewitz M, et al: Influence of preparation and wall thickness on the resistance to fracture of zirconia implant abutments. Clin Implant Dent Relat Res 2012;14 Suppl 1:e196-203

24. Kelly JR, Rungruanganunt $\mathrm{P}$, Hunter B, et al: Development of a clinically validated bulk failure test for ceramic crowns. J Prosthet Dent 2010;104:228-238

25. Lee CK, Karl M, Kelly JR: Evaluation of test protocol variables for dental implant fatigue research. Dent Mater 2009;25:1419-1425

26. International Organization for Standardization (ISO). Dentistry-Implants-Dynamic Fatigue Test for Endosseous Dental Implants; ISO 14801:2007; ISO: Geneva, Switzerland, 2007

This article is protected by copyright. All rights reserved. 
27. Fraga S, Pereira GKR, Freitas M, et al: Loading frequencies up to $20 \mathrm{~Hz}$ as an alternative to accelerate fatigue strength tests in a Y-TZP ceramic. J Mech Behav Biomed Mater 2016;61:79-86

28. Magne P, Schlichting LH, Maia HP, et al: In vitro fatigue resistance of CAD/CAM composite resin and ceramic posterior occlusal veneers. J Prosthet Dent 2010;104:149-

157

29. Elsayed A, Wille S, Al-Akhali M, et al: Comparison of fracture strength and failure mode of different ceramic implant abutments. J Prosthet Dent 2017;117:499-506

30 Costa AK, Borges AL, Fleming GJ, et al: The strength of sintered and adhesively bonded Zirconia/veneer-ceramic bilayers. J Dent 2014;42:1269-1276

31. Costa AK, Kelly RD, Fleming GJ, et al: Laminated ceramics with elastic interfaces: a mechanical advantage? J Dent 2015;43:335-341

32-Luangruangrong P, Cook NB, Sabrah AH, et al: Influence of full-contour zirconia surface roughness on wear of glass-ceramics. J Prosthodont 2014;23:198-205

33. Gibbs $\mathrm{CH}$, Mahan PE, Lundeen $\mathrm{HC}$, et al: Occlusal forces during chewing and swallowing as measured by sound transmission. J Prosthet Dent 1981;46:443-449

Gibbs CH, Mahan PE, Mauderli A, et al: Limits of human bite strength. J Prosthet Dent 1986;56:226-229

35. Haraldson T, Carlsson GE, Ingervall B: Functional state, bite force and postural muscle activity in patients with osseointegrated oral implant bridges. Acta Odontol Scand 1979;37:195-206

36. Rocca GT, Sedlakova P, Saratti CM, et al: Fatigue behavior of resin-modified monolithic CAD-CAM RNC crowns and endocrowns. Dent Mater 2016;32:e338-e350

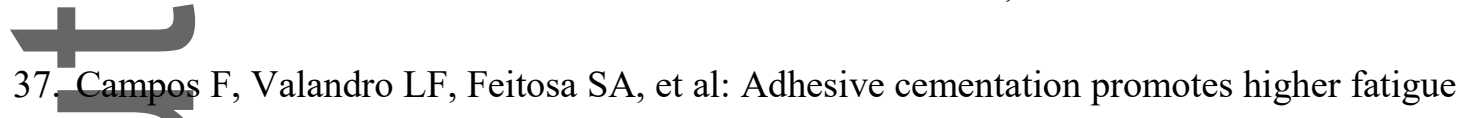
resistance to zirconia crowns. Oper Dent 2017;42:215-224

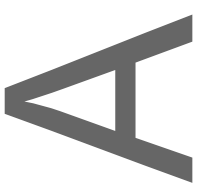

This article is protected by copyright. All rights reserved. 


\section{FIGURES}

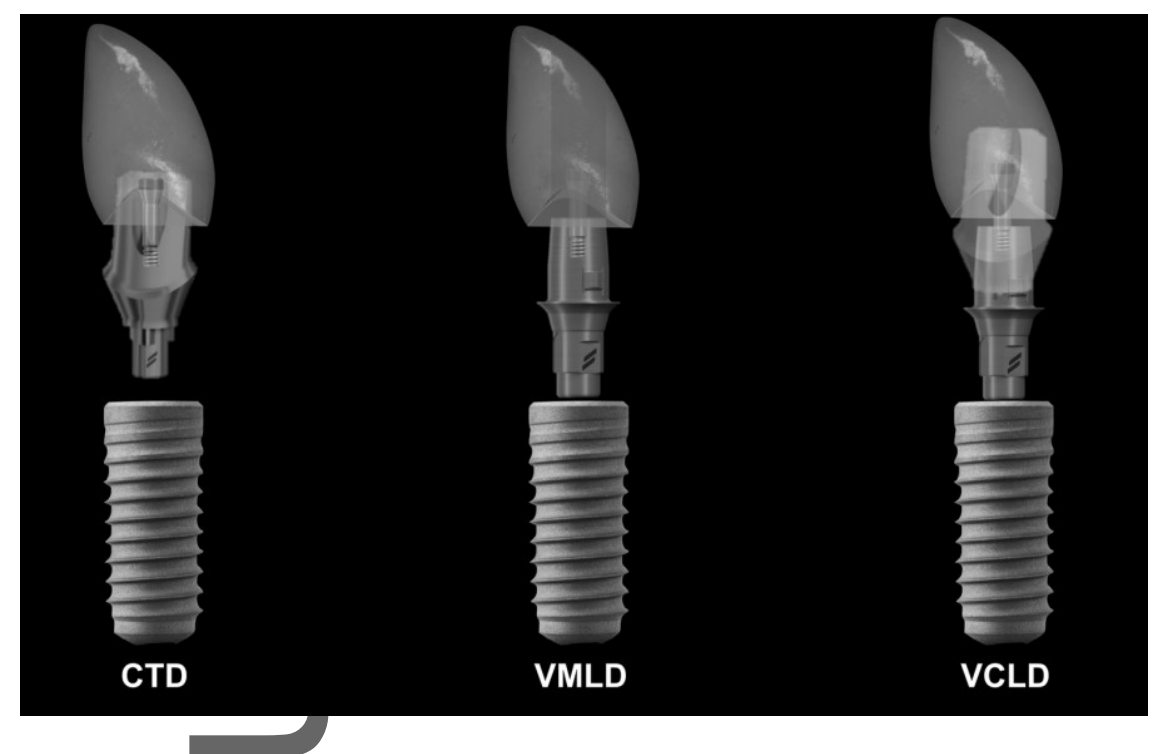

Figure 1 An assembly of all components of abutment and crown in three design groups (CTD: lithium disilicate crowns cemented on custom-milled titanium abutments; VMLD: monolithic fullcontour lithium disilicate crowns cemented on a chairside titanium base; and VCLD: lithium disilicate crowns bonded to lithium disilicate customized anatomic structures and then cemented onto a chairside titanium base).
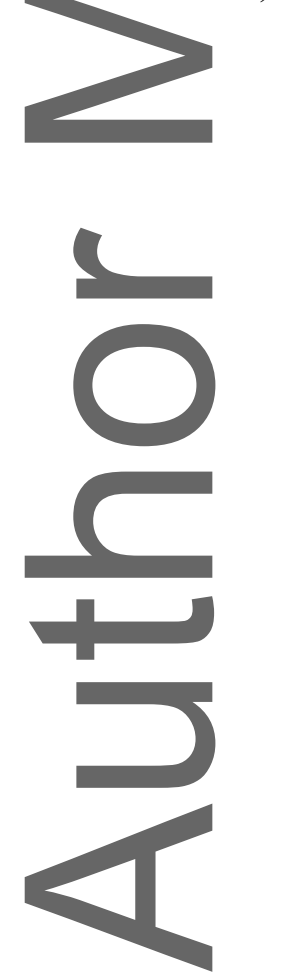

This article is protected by copyright. All rights reserved. 

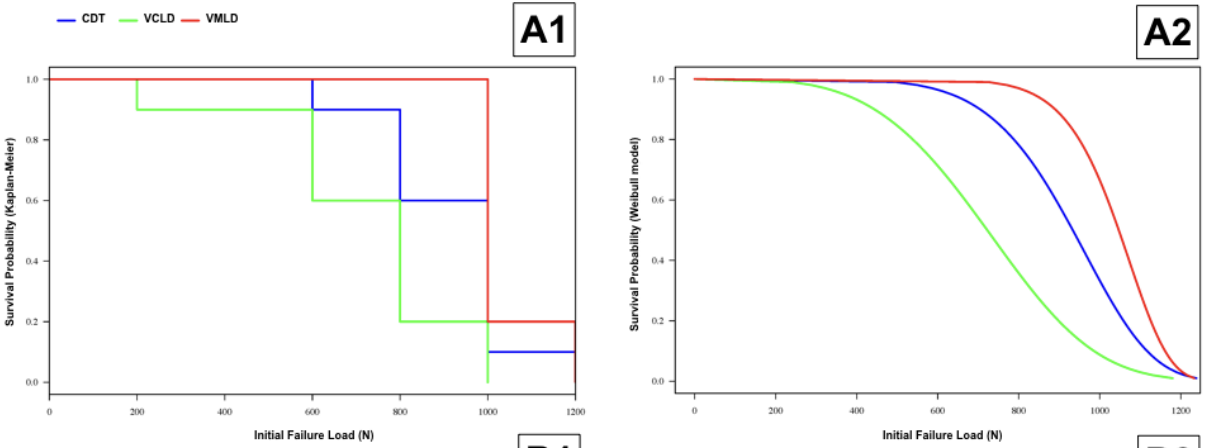

B1
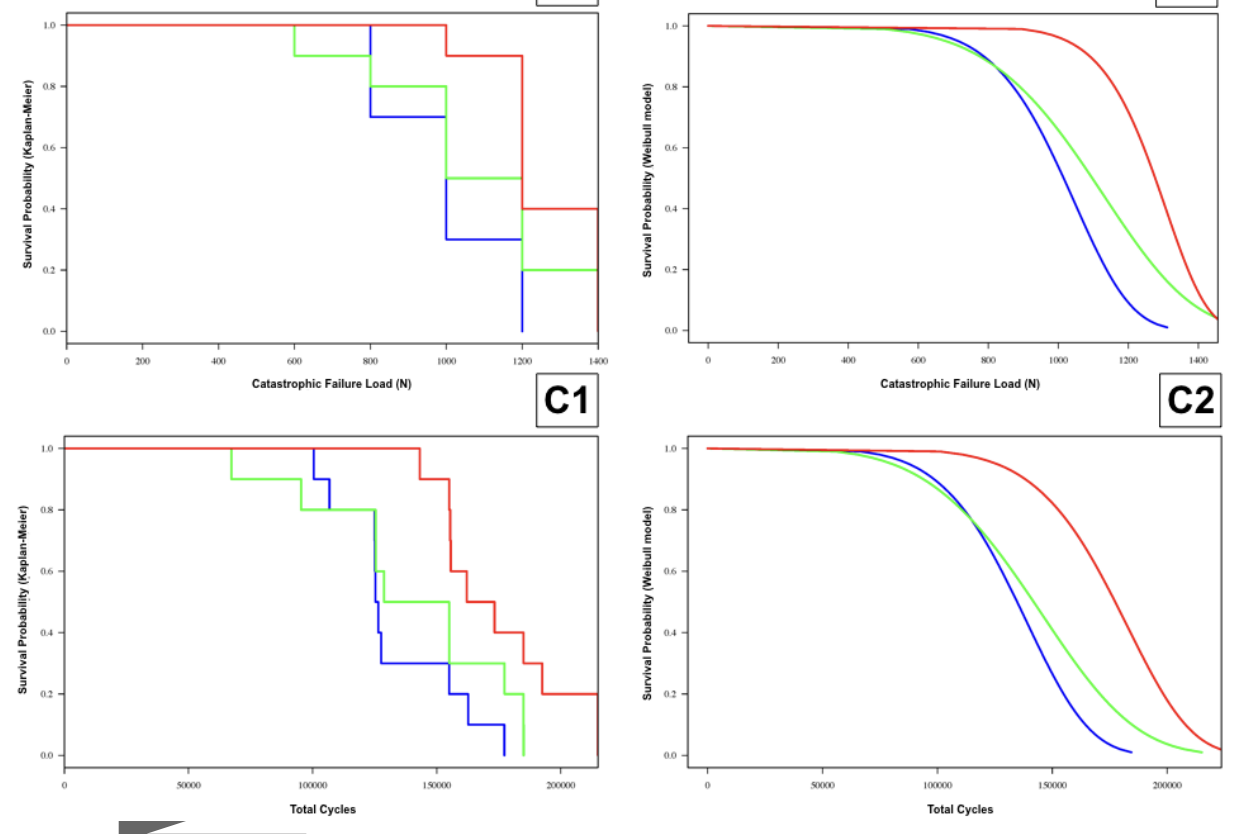

Figure 2 Results of survival probability Kaplan-Meier (A1, B1, C1) and Weibull model (A2, B2, $\mathrm{C} 2) .(\mathrm{A} 1 \rightarrow \mathrm{A} 2)$ : Initial failure included any crack on the ceramic structure at the end of each cycle; $(\mathrm{B} 1 \rightarrow \mathrm{B} 2)$ : Catastrophic failure included the fracture of any components (i.e., implant or crown); and $(\mathrm{C} 1 \rightarrow \mathrm{C} 2)$ : number of total cycles until catastrophic failure occurred.

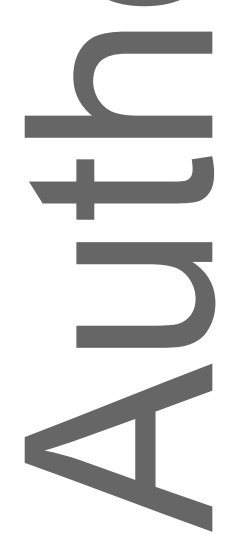

This article is protected by copyright. All rights reserved. 

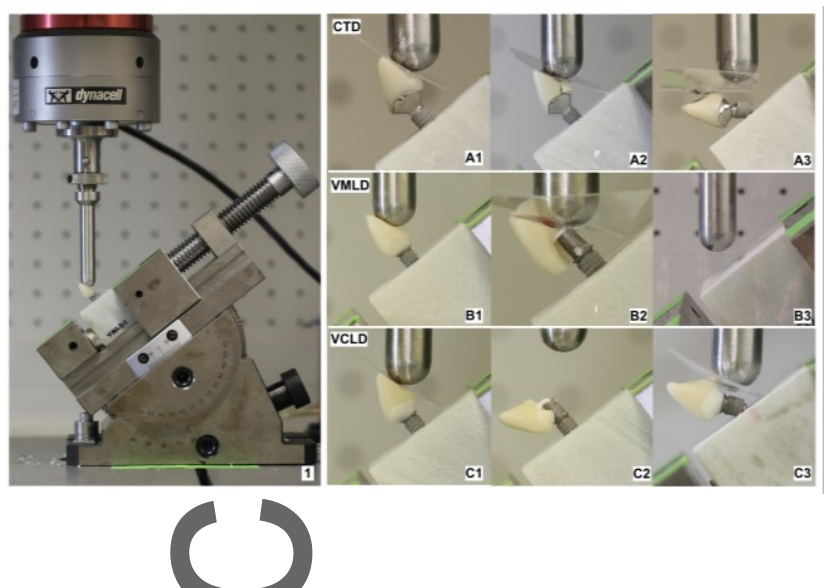

Figure 3 (1) Representative macrograph illustrating specimen positioned in Instron ElectroPuls E3000 machine for fatigue loading test. $(\mathrm{A} 1 \rightarrow \mathrm{C} 3)$ Representative macrograph illustrating the mode of failure. Group CTD (A1): Before fatigue loading; (A2): Catastrophic failure localized on cingulum of lithium disilicate crown; (A3): Catastrophic failure of both implant and abutment screw. Group VMLD (B1): Before fatigue loading; (B2): Catastrophic failure localized on screw channel of monolithic lithium disilicate crown; (B3): Catastrophic failure of both implant and abutment screw. Group VCLD (C1): Before fatigue loading; (C2): Catastrophic failure of both of lithium disilicate customized anatomical structure and lithium disilicate crown fracture; (C3): Catastrophic failure of both implant and abutment screw.
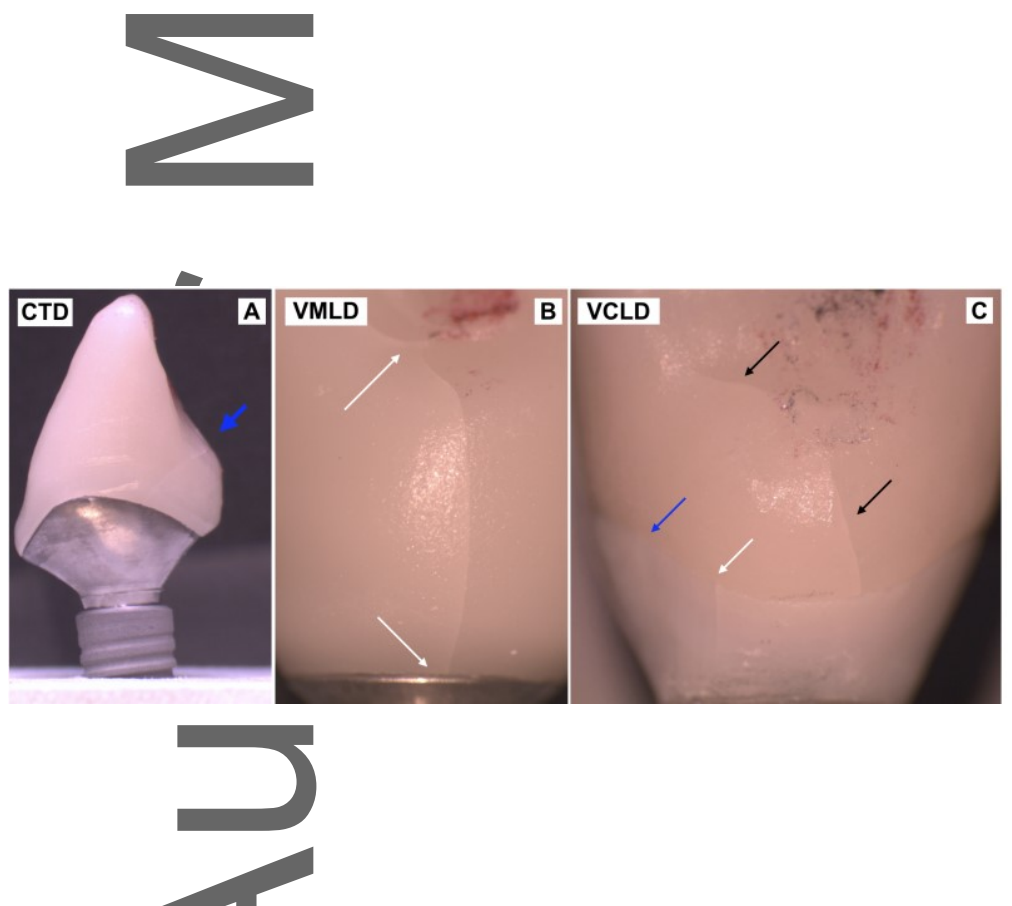

Figure 4-Representative stereomicroscope images of the fractured restorations: (A) CTD specimen with a crack line on lithium disilicate crown at $800 \mathrm{~N}$ (blue arrow) $(0.8 \times$ magnification); (B) VMLD specimen with a crack line (white arrow) associated with screw channel on lingual aspect and titanium

This article is protected by copyright. All rights reserved. 
base at $1000 \mathrm{~N}(2.5 \times$ magnification); (C) VCLD specimen with a crack line on lithium disilicate customizes anatomical structure at $800 \mathrm{~N}$ (blue arrow), $1000 \mathrm{~N}$ (white arrow), and $1200 \mathrm{~N}$ on crown (black arrow) (2.25x magnification).

List of Tables
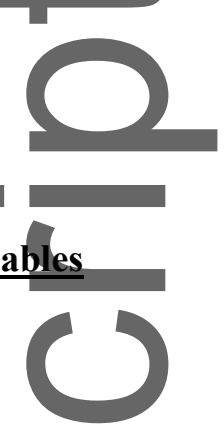

Table 1 Materials used

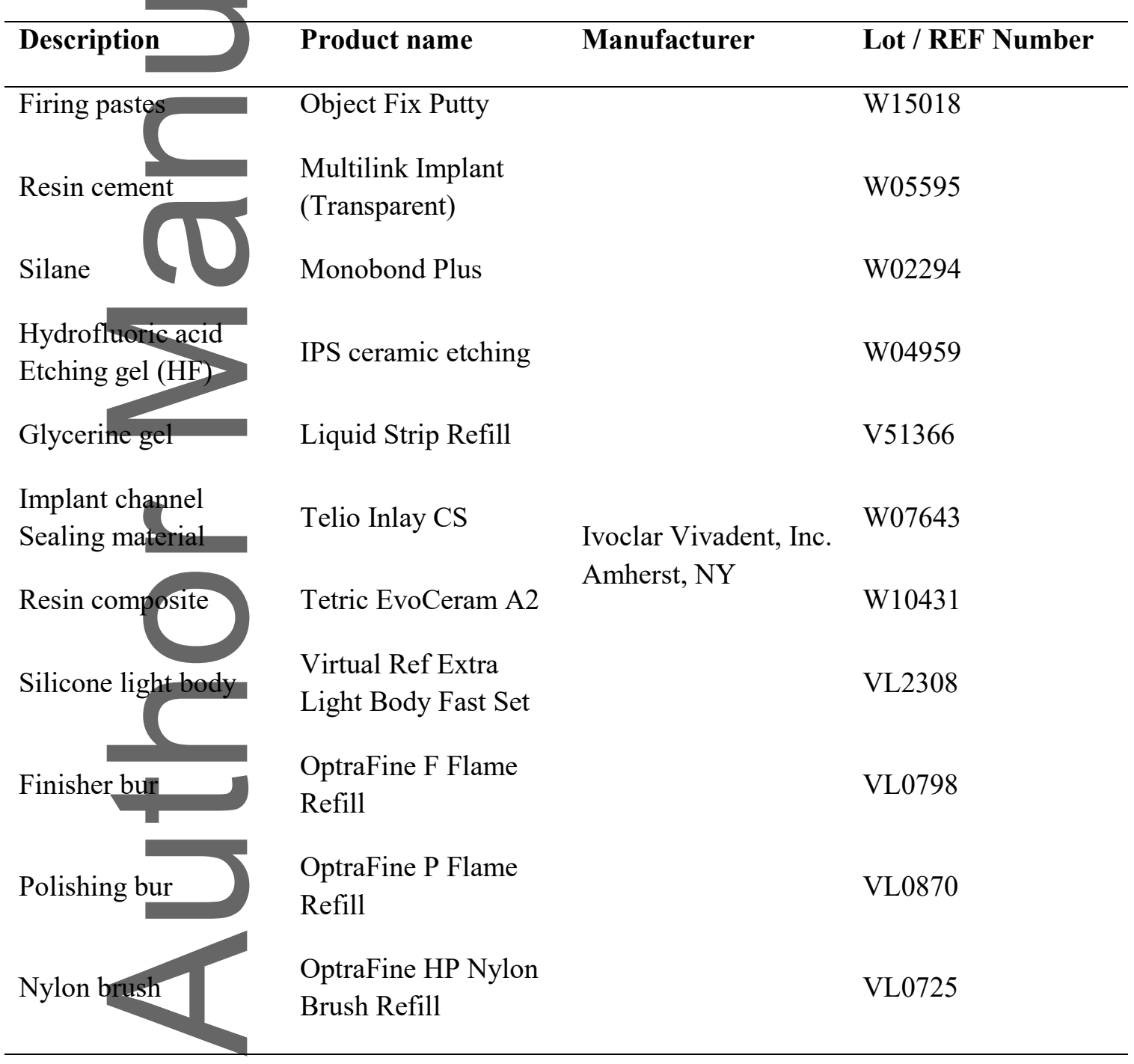

This article is protected by copyright. All rights reserved. 


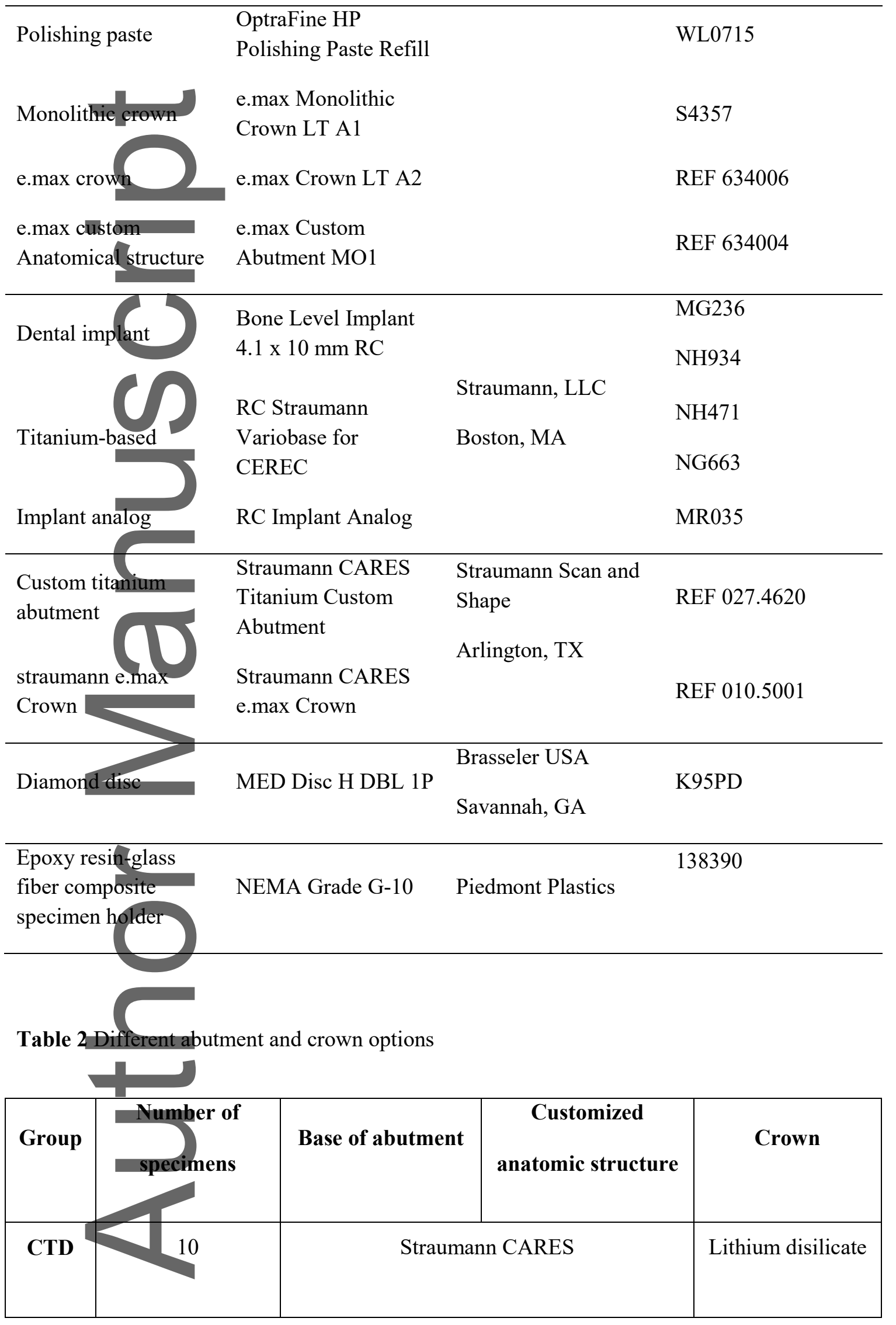

This article is protected by copyright. All rights reserved. 


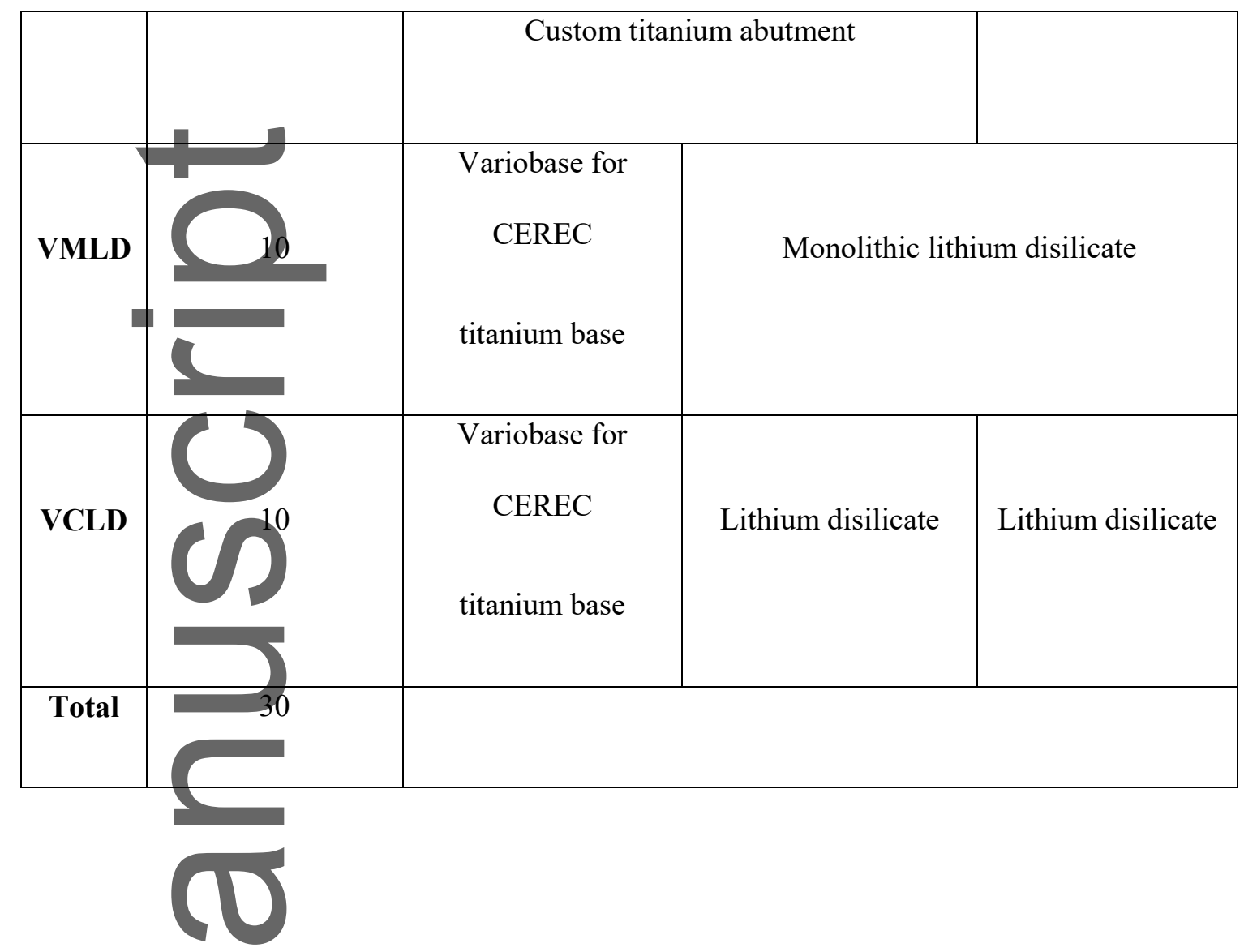

Table 3 The summary table of initial, catastrophic failure loads and number of cycles.

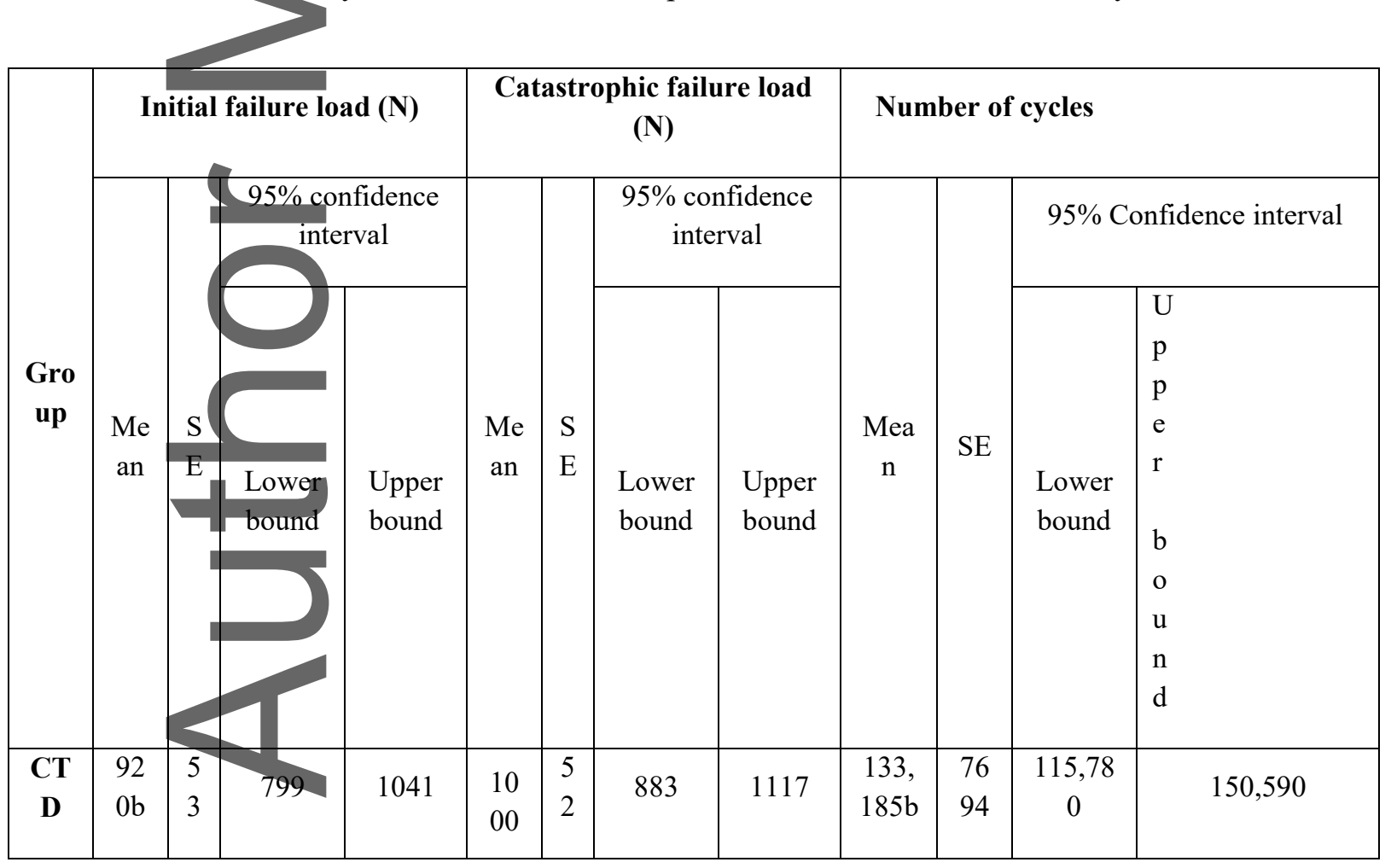

This article is protected by copyright. All rights reserved. 


\begin{tabular}{|c|c|c|c|c|c|c|c|c|c|c|c|}
\hline $\begin{array}{l}\text { VM } \\
\text { LD }\end{array}$ & $\begin{array}{l}10 \\
40\end{array}$ & \begin{tabular}{l|l}
2 & 9 \\
7 & 9
\end{tabular} & 1100 & $\begin{array}{c}12 \\
60 a\end{array}$ & $\begin{array}{l}4 \\
3\end{array}$ & 1163 & 1357 & $\begin{array}{l}175 \\
231 \mathrm{a}\end{array}$ & $\begin{array}{l}81 \\
26\end{array}$ & $\begin{array}{c}156,84 \\
7\end{array}$ & 193,614 \\
\hline $\begin{array}{l}\text { VC } \\
\text { LD }\end{array}$ & $\begin{array}{l}72 \\
0 \mathrm{a}\end{array}$ & 4 & 888 & $\begin{array}{c}10 \\
80 \\
\mathrm{~b}\end{array}$ & $\begin{array}{l}8 \\
0\end{array}$ & 899 & 1261 & $\begin{array}{c}139 \\
965 b\end{array}$ & $\begin{array}{c}12 \\
35 \\
2\end{array}$ & $\begin{array}{c}112,02 \\
2\end{array}$ & 167,908 \\
\hline
\end{tabular}

The same lower case letters denote no significant statistical difference.

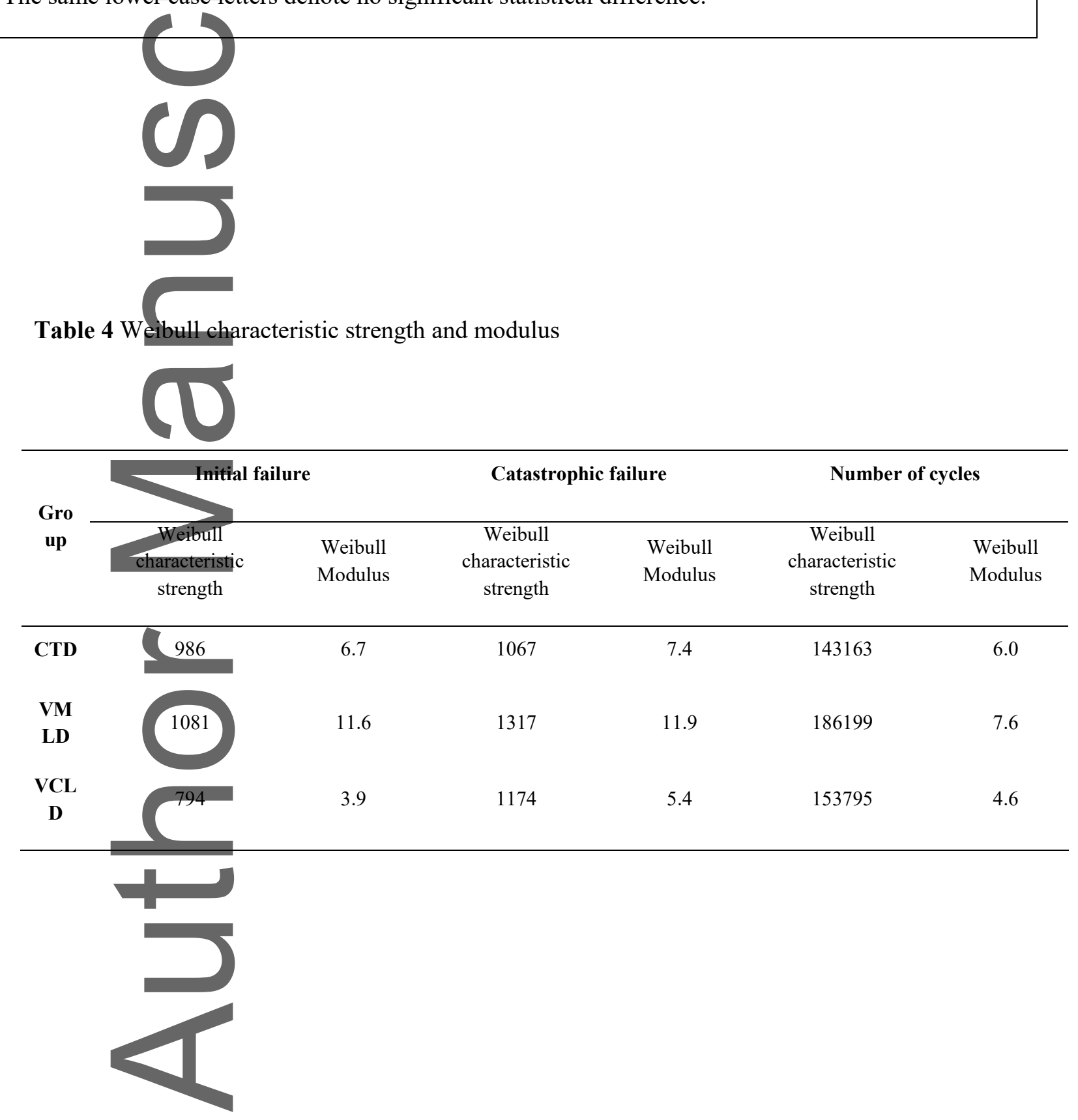

This article is protected by copyright. All rights reserved. 
Table 5 Mode of failure at catastrophic failure load $(n=10)$ related to fracture locations (N/A means no specific component on specific restorative design)

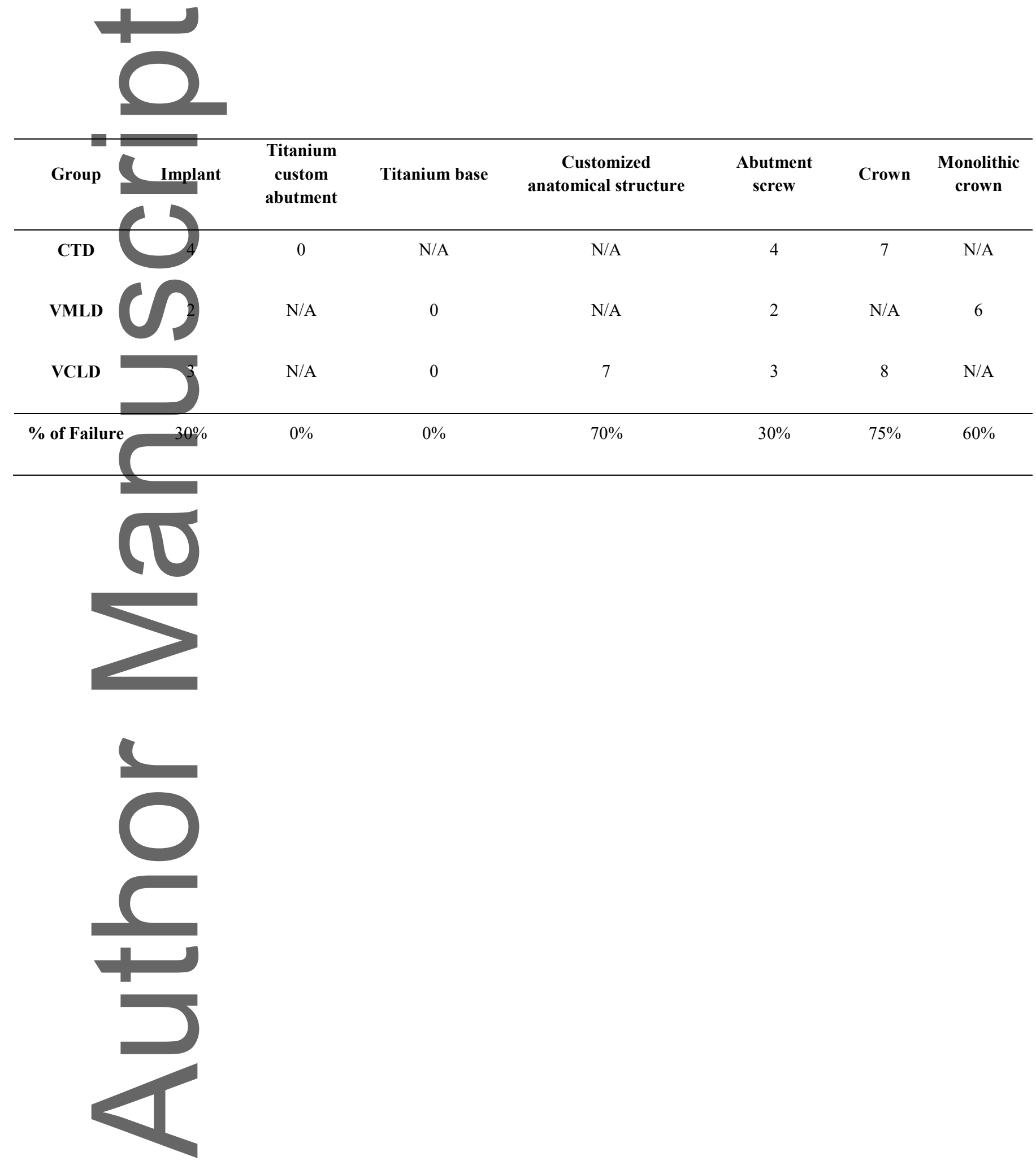

This article is protected by copyright. All rights reserved. 